\title{
GMR
}

\section{Anti-inflammatory effects of essential oils from Mangifera indica}

\author{
R.M. Oliveira ${ }^{1}$, T.S. Dutra ${ }^{1}$, E. Simionatto ${ }^{3}$, N. Ré Re C.A.L. Kassuya $^{2}$ and \\ C.A.L. Cardoso ${ }^{4}$
}

${ }^{1}$ Laboratório de Química Analítica, Instituto de Química, Universidade Federal de Mato Grosso do Sul, Campo Grande, MS, Brasil ${ }^{2}$ Laboratório de Imunoinflamação e Dor, Faculdade de Ciências da Saúde, Universidade Federal da Grande Dourados, Dourados, MS, Brasil ${ }^{3}$ Laboratório de Produtos Naturais, Curso de Química, Universidade Estadual de Mato Grosso do Sul, Navirai, MS, Brasil ${ }^{4}$ Laboratório de Análise Instrumental, Centro de Estudos em Recursos Naturais, Universidade Estadual de Mato Grosso do Sul, Dourados, MS, Brasil

Corresponding author: C.A.L. Cardoso

E-mail: claudia@uems.br

Genet. Mol. Res. 16 (1): gmr16019227

Received September 9, 2016

Accepted December 7, 2016

Published March 16, 2017

DOI http://dx.doi.org/10.4238/gmr16019227

Copyright (C) 2017 The Authors. This is an open-access article distributed under the terms of the Creative Commons Attribution ShareAlike (CC BY-SA) 4.0 License.

ABSTRACT. Mangifera indica is widely found in Brazil, and its
leaves are used as an anti-inflammatory agent in folk medicine. The
aim of this study is to perform composition analysis of essential oils
from the $M$. indica varieties, espada (EOMIL1) and coração de boi
(EOMIL2), and confirm their anti-inflammatory properties. Twenty-
three volatile compounds were identified via gas chromatography-
mass spectrometry (GC-MS) in two essential oils from the leaves.
Paw edema and myeloperoxidase (MPO) activity were evaluated using
the carrageenan-induced paw model, while leukocyte migration was
analyzed using the pleurisy model. At oral doses of 100 and $300 \mathrm{mg} / \mathrm{kg}$,
the essential oils significantly reduced edema formation and the increase
in MPO activity induced by carrageenan in rat paws. For a dose of 300
mg/kg EOMIL1, $62 \pm 8 \%$ inhibition of edema was observed, while

Genetics and Molecular Research 16 (1): gmr16019227 
EOMIL2 led to $51 \pm 7 \%$ inhibition of edema. At a dose of $100 \mathrm{mg} / \mathrm{kg}$, the inhibition was $54 \pm 9 \%$ for EOMIL1 and $37 \pm 7 \%$ for EOMIL2. EOMIL1 and EOMIL2 significantly reduced MPO activity at doses of $100 \mathrm{mg} / \mathrm{kg}$ (47 \pm 5 and $23 \pm 8 \%$, respectively) and $300 \mathrm{mg} / \mathrm{kg}$ (50 \pm 9 and $31 \pm 7 \%$, respectively). In the pleurisy model, inhibitions were also observed for EOMIL1 and EOMIL2 in the leukocyte migration test. The results of the present study show that essential oils from $M$. indica differ in chemical composition and anti-inflammatory activity in rats.

Key words: Espada; Coração de boi; Paw edema; Pleurisy; Rats

\section{INTRODUCTION}

The volatile oils from plants are known for their biological properties, especially antibacterial, antifungal, and antioxidant effects (Deans and Waterman, 1993). In addition, there has been an increased interest in the use of new volatile oils in the pharmaceutical, food, and cosmetic industries.

The species Mangifera indica L., which belongs to the Anacardiaceae family, is one of the 40 species of the Mangifera genus that can be found in the tropical and subtropical regions of Southeast Asia, Africa, and Latin America (Nikhal and Mahajan, 2010). The leaves of M. indica have been used in the Indian systems of medicine to treat diseases such as asthma, dysentery, cough, leucorrhea, jaundice, pain, and malaria (Basha et al., 2011). Studies have been conducted on aqueous extracts of the bark of a selected variety of $M$. indica, which have been used in the pharmaceutical formulation named Vimang ${ }^{\circledR}$. The volatile constituents of the fruits of $M$. indica present considerable variation in their chemical composition, and they have been extensively investigated (Dzamic et al., 2010). The variability of the volatile constituents can be influenced by factors, such as stage of development, variety, and method of extraction (Pino et al., 2005).

The volatile compounds in $M$. indica are normally obtained via hydrodistillation and analyzed through gas chromatography-mass spectrometry (GC-MS) (Pino et al., 2005; Moreno et al., 2010; Dzamic et al., 2010). In the present study, the anti-inflammatory effects and chemical composition of essential oils from the leaves of $M$. indica were evaluated.

\section{MATERIAL AND METHODS}

\section{Collection and material selection}

The leaves of $M$. indica varieties espada and coração de boi were collected between November 2011 and May 2012 from two trees in the town of Campo Grande, Mato Grosso do Sul State, Brazil. The varieties espada (collected in location on the geographical coordinates $20^{\circ} 30^{\prime} 7^{\prime \prime S}$ and $\left.54^{\circ} 37^{\prime} 17^{\prime \prime} \mathrm{W}\right)$ and coracão de boi $\left(20^{\circ} 30^{\prime} 13^{\prime \prime} \mathrm{S}\right.$ and $\left.54^{\circ} 37^{\prime} 14^{\prime \prime} \mathrm{W}\right)$ were identified by Dr. Ronaldo Posella Zaccaro (Centro Universitário Moura Lacerda, Ribeirão Preto, SP, Brazil).

\section{Extraction}

After collection, the samples were immediately subjected to the extraction of essential

Genetics and Molecular Research 16 (1): gmr16019227 
oils. Oils from $200 \mathrm{~g}$ of fresh leaves were extracted via hydrodistillation in a modified Clevenger apparatus with $3 \mathrm{~L}$ water for $4 \mathrm{~h}$. The oil was collected in a glass vial with a small amount of water and stocked in a freezer for use in chromatographic analysis. Consecutive extractions from $200 \mathrm{~g}$ leaves were performed to obtain the amount of oil sufficient for testing the anti-inflammatory activity.

\section{Chromatographic analysis}

The analyses of oil were performed with Varian GC-MS system comprising a CP3900 gas chromatograph (Walnut Creek, CA, USA) and an ion-trap mass spectrometer (Saturn $2100-\mathrm{T} / \mathrm{MS} / \mathrm{MS}$ ). Chromatographic separation was performed in a silica capillary column with 5\%-Phenyl-Arylene-95\%-Dimethylpolysiloxane (ZB-5 MS) as the stationary phase. The column was $30 \mathrm{~cm}$ in length with an inner diameter of $0.25 \mathrm{~mm}$ and film thickness of $0.25 \mu \mathrm{m}$. The initial temperature of the furnace was $50^{\circ} \mathrm{C}$, followed by heating from $50^{\circ}$ to $250^{\circ} \mathrm{C}$ at $3^{\circ} \mathrm{C} / \mathrm{min}$. One microliter hexane solution was injected in split mode $(1: 20)$. The temperatures of the manifold, GC-MS interface, and ion trap were $50^{\circ}, 250^{\circ}$, and $200^{\circ} \mathrm{C}$, respectively. The MS scan parameters included electron-impact ionization voltage of $70 \mathrm{eV}$, mass range of 40$450 \mathrm{~m} / \mathrm{z}$, and scan interval of $0.5 \mathrm{~s}$. Saturn GC/MS Workstation Version 5.52 software was used for instrument control and data treatment. The retention indices (RI) were calculated using the retention times of linear alkanes $\left(\mathrm{C}_{9}-\mathrm{C}_{22}\right)$ and retention data of the essential oil components. The volatile compounds were identified by comparing their RI with those of the compounds described by Adams (2007) and their mass spectra with the data in NIST 2.1 and Saturn Libraries.

\section{Animals}

The experiments were conducted with male Wistar rats (150-200 g) and Swiss mice (20-30 g), housed ( 5 animals per cage) at $22^{\circ} \pm 2^{\circ} \mathrm{C}$ under a $12 \mathrm{~h} \mathrm{light} / 12 \mathrm{~h}$ dark cycle (lights on at 06:00). The rats were provided ad libitum access to food and water. One hour after the experiments, the animals were divided into groups $(\mathrm{N}=6)$ and acclimatized to laboratory conditions. The experiments were carried out according to the protocol of the Institutional Ethics Committee and in accordance with the guidelines for the care of laboratory animals and ethical guidelines (Zimmermann, 1983).

\section{Drugs}

The following substances were used: lambda carrageenan type IV (Sigma-Aldrich Co., St. Louis, USA), dexamethasone (Sigma Co., St. Louis, USA), and essential oils from $M$. indica varieties 1 (EOMIL1) and 2 (EOMIL2). All drugs used in this study were dissolved in saline, except EOMIL1 and EOMIL2, which were dissolved in Tween 80 plus saline. The final concentration of Tween 80 (Sigma-Aldrich Co., St. Louis, MO, USA) did not exceed 10\%, and it did not induce any pharmacological effect.

\section{Measurement of paw edema induced by carrageenan}

The test animals received $100 \mu \mathrm{L}$ subcutaneous injection of saline solution $(0.9 \%)$

Genetics and Molecular Research 16 (1): gmr16019227 
containing carrageenan $(300 \mu \mathrm{g})$ into the right paw. The contralateral paw received $100 \mu \mathrm{L}$ subcutaneous injection of saline $(0.9 \%)$. The rats were pretreated ( $1 \mathrm{~h}$ before carrageenan) through the oral route [peroral (po)] with vehicle (solution of saline $0.9 \%$ with $10 \%$ Tween 80, control group), EOMIL1 and EOMIL2 at doses 100 and $300 \mathrm{mg} / \mathrm{kg}$, and dexamethasone $(1.0 \mathrm{mg} / \mathrm{kg}$, subcutaneous route, positive control). The thickness of the rat paw (Sharma et al., 2004) was measured using a digital micrometer before induction of edema and $2 \mathrm{~h}$ after the injection of inflammatory agent.

\section{Analysis of myeloperoxidase activity}

To verify whether EOMIL1 and EOMIL2 can interfere with neutrophil migration induced by carrageenan, myeloperoxidase (MPO) activity was measured in the skin of the rat paw. Six hours after the carrageenan injection, the rats were euthanized in order to measure the MPO activity (De Young et al., 1989). A homogenate was prepared from each paw skin by homogenization of tissues in 5\% (w/v) $80 \mathrm{mM}$ phosphate buffer, $\mathrm{pH} \mathrm{5.4,} \mathrm{containing} 0.5 \%$ hexadecyltrimethylammonium bromide. Next, it was centrifuged at $11.500 \mathrm{~g}$ for $20 \mathrm{~min}$ at $4^{\circ} \mathrm{C}$. The supernatant of each sample $(30 \mu \mathrm{L})$ was mixed with $100 \mu \mathrm{L} 80 \mathrm{mM}$ phosphate buffer, 85 $\mu \mathrm{L} 0.22 \mathrm{M}$ phosphate buffer, and $15 \mu \mathrm{L} 0.017 \%$ hydrogen peroxide on a 96-well plate. The reaction was triggered by the addition of $20 \mu \mathrm{L}$ 3,3,3-tetramethylbenzidine (dissolved in N,Ndimethylformamide). The plate was kept at $37^{\circ} \mathrm{C}$ for $3 \mathrm{~min}$, after which the reaction was stopped by adding $30 \mu \mathrm{L} 1.46 \mathrm{M}$ sodium acetate ( $\mathrm{pH}$ 3.0. The enzymatic activity was determined by measuring the optical density at $630 \mathrm{~nm}$, and it was expressed as mean optical density per $\mathrm{mg}$ of protein. All reagents were purchased from Sigma-Aldrich Co., St. Louis, USA.

\section{Pleural cell migration and protein exudation}

The mice were divided into six groups. The first group (naive group) received vehicle alone, without the carrageenan pleural injection. All others group received carrageenan 1 $\mathrm{h}$ after oral/subcutaneous treatment. The groups were formed as follows: the control group received vehicle alone; group 2 received $100 \mathrm{mg} / \mathrm{kg}$ EOMIL1; group 3: $300 \mathrm{mg} / \mathrm{kg}$ of EOMIL1; group 4: $100 \mathrm{mg} / \mathrm{kg}$ of EOMIL2; group 5: $300 \mathrm{mg} / \mathrm{kg}$ of EOMIL2; and group 6: 1.0 $\mathrm{mg} / \mathrm{kg}$ dexamethasone (subcutaneously, positive control). Pleurisy was induced through an intrapleural injection of $100 \mu \mathrm{L} \mathrm{1 \%}$ carrageenan as previously described (Velo et al., 1973). Carrageenan was diluted in saline buffer. Briefly, an adapted needle was inserted into the right side of the thoracic cavity of animals to enable intrapleural administration of carrageenan. The naive mice received an equal volume $(100 \mu \mathrm{L})$ of sterile, pyrogen-free saline. After $4 \mathrm{~h}$, the animals were killed, and the pleural cavity was washed with $1 \mathrm{~mL}$ phosphate-buffered saline. The exudate volume was measured. An aliquot of $20 \mu \mathrm{L}$ exudate was diluted with Turck solution (1:20) and used for total leukocyte count in a Neubauer chamber. Protein exudation was evaluated using a Bradford assay kit (Bioagency, São Paulo, Brazil). The total cell count was measured under a light microscope, and the results were reported as the number of cells per $\mathrm{mL}$ of pleural fluid.

\section{Statistical analysis}

The results are reported as means $\pm \mathrm{SE}$ (standard error of the mean) of experiments.

Genetics and Molecular Research 16 (1): gmr16019227 
The statistical significance among the groups was assessed via one-way analysis of variance according to the Student-Newman-Keuls test. Comparisons between the control and vehicle groups were analyzed using the Student $t$-test. P values less than 0.05 were considered statistically significant.

\section{RESULTS AND DISCUSSION}

The percentage yields $(\mathrm{w} / \mathrm{w})$ of essential oils obtained through the hydrodistillation of $M$. indica leaves were $0.01 \%$ for both varieties. In the two essential oils obtained from the two $M$. indica varieties, 23 volatile compounds were tentatively identified and characterized as monoterpenes and sesquiterpenes. The retention times in GC-MS were determined from three independent experiments showing a coefficient of variation less than $2 \%$.

A comparison of the two essential oils revealed qualitative and quantitative differences in composition (Table 1). In the essential oil obtained from the variety espada, the major compounds were sesquiterpenes, such as $\beta$-selinene (34.90\%), cyperene (22.40\%), (E)-caryophyllene $(16.39 \%), \alpha$-humulene $(10.84 \%)$, terpinolene $(2.31 \%)$, and $\alpha$-selinene (2.31\%). In the essential oil obtained from the variety coração de boi, the major compounds were cyperene $(32.62 \%),(\mathrm{E})$-caryophyllene $(26.91 \%)$, $\alpha$-humulene $(17.12 \%)$, terpinolene $(2.32 \%), \beta$-selinene $(5.70 \%)$, and myrcene $(2.80 \%)$. These compounds were also reported to be the most important constituents in the leaves of the variety coquinho analyzed by GC-MS (Gebara et al., 2011).

Table 1. Percentage composition of volatile compounds of the leaves of Mangifera indica.

\begin{tabular}{|c|c|c|c|c|}
\hline \multirow[t]{2}{*}{ Compounds } & \multirow[t]{2}{*}{$\mathrm{KI}^{\mathrm{a}}$} & \multirow[t]{2}{*}{$\mathrm{KI}^{\mathrm{b}}$} & \multicolumn{2}{|c|}{ Relative composition (\%) } \\
\hline & & & Espada & Coração de boi \\
\hline$\alpha$-thujene & 931 & 931 & 0.11 & 1.71 \\
\hline Sabinense & 974 & 976 & - & 0.13 \\
\hline myrcene & 990 & 991 & - & 2.80 \\
\hline 3-Hexen-1-olacetate & 1006 & 1004 & - & 0.71 \\
\hline$\gamma$-carene & 1011 & 1011 & 0.51 & - \\
\hline$o$-cimene & 1020 & 1022 & 1.00 & 0.11 \\
\hline Limonene & 1026 & 1031 & 0.10 & 1.41 \\
\hline$\beta$-phellandrene & 1029 & 1031 & 0.12 & 2.70 \\
\hline Cisocimene & 1035 & 1034 & - & 0.70 \\
\hline Terpinolene & 1083 & 1086 & 2.32 & - \\
\hline$p$-cimenene & 1089 & 1089 & 0.11 & - \\
\hline$p$-cimen-8-ol & 1187 & 1183 & 0.11 & - \\
\hline$\delta$-elemene & 1332 & 1339 & 0.12 & 0.10 \\
\hline Ciclosativene & 1366 & 1368 & - & 0.10 \\
\hline Isoledene & 1370 & 1373 & 0.12 & 0.10 \\
\hline$\beta$-elemene & 1385 & 1391 & 1.43 & 0.51 \\
\hline Cyperene & 1402 & 1398 & 22.40 & 32.62 \\
\hline$\alpha$-gurjunene & 1407 & 1409 & 0.52 & 0.72 \\
\hline (E)-Caryophyllene & 1414 & 1418 & 16.39 & 26.91 \\
\hline$\alpha$-humulene & 1450 & 1454 & 10.84 & 17.12 \\
\hline Allo-aromadendrene & 1454 & 1461 & 1.73 & 2.03 \\
\hline Drima-7.9(11)diene & 1465 & 1469 & 2.11 & - \\
\hline$\gamma$-gurjunene & 1467 & 1473 & 0.71 & 1.71 \\
\hline$\gamma$-murolene & 1476 & 1477 & 0.71 & 0.40 \\
\hline$\beta$-Selinene & 1485 & 1485 & 34.90 & 5.70 \\
\hline Viridiflorene & 1492 & 1493 & - & 1.10 \\
\hline$\alpha$-selinene & 1494 & 1494 & 2.31 & - \\
\hline$\gamma$-cadinene & 1514 & 1513 & 1.21 & 0.50 \\
\hline caryophylleno oxide & 1576 & 1581 & 0.80 & 0.30 \\
\hline
\end{tabular}

$\mathrm{KI}^{a}$ : Retention index calculated. $\mathrm{KI}^{\mathrm{b}}$ : Retention index literature from Adams, 2007. (-): not identified. Espada $=$ essential oil of mango variety espada. Coração de boi = essential oil of mango variety coração de boi.

Genetics and Molecular Research 16 (1): gmr16019227 
Some studies show that the main compounds of the essential oils obtained from mango leaves in countries, such as Brazil, Nigeria, China, and Colombia, are sesquiterpenes [e.g., (E)-caryophyllene, caryophyllene oxide, $\delta$-carene, $\alpha$-gurjunene, $\beta$-selinene, and humulene epoxide] and monoterpenes (e.g., $\beta$-pinene, $\alpha$-pinene, limonene, myrcene, cis- and trans ocimene) (Pino et al., 20005; Moreno et al., 2010; Dzamic et al., 2010). These results corroborate with the data on the composition of $M$. indica leaves in the espada and coração de boi varieties.

Although this plant has been used in the treatment of various inflammatory diseases, the pharmacological importance of these essential oils has not yet been scientifically demonstrated.

Several pharmaceutical products currently used to treat inflammation are not completely efficient in chronic diseases, and they produce several side effects. Therefore, it is necessary to develop more effective and less toxic agents (Hoff Brait et al., 2015). The identification of compounds capable of interacting with molecular targets responsible for the amplification of inflammatory processes is a very interesting field of research.

The results depicted in Figure 1A $(100 \mathrm{mg} / \mathrm{kg})$ and Figure 1B $(300 \mathrm{mg} / \mathrm{kg})$ show that EOMIL1 or EOMIL2 significantly reduced edema formation at oral doses of 100 and $300 \mathrm{mg} /$ $\mathrm{kg}$. In the carrageenan-induced edema model, at a dose of $100 \mathrm{mg} / \mathrm{kg}, 54 \pm 9 \%$ inhibition of edema for EOMIL1 and $37 \pm 7 \%$ inhibition for EOMIL2 were observed. However, for the positive control in paw edema model, dexamethasone $(1 \mathrm{mg} / \mathrm{kg}$, subcutaneous route) showed $75 \pm 4 \%$ inhibition of edema (Figure 1A).

At $300 \mathrm{mg} / \mathrm{kg}$, maximal inhibition, with $62 \pm 8 \%$ inhibition of edema, was observed for EOMIL1, while the inhibition for EOMIL2 was $51 \pm 7 \%$ (Figure 1B).
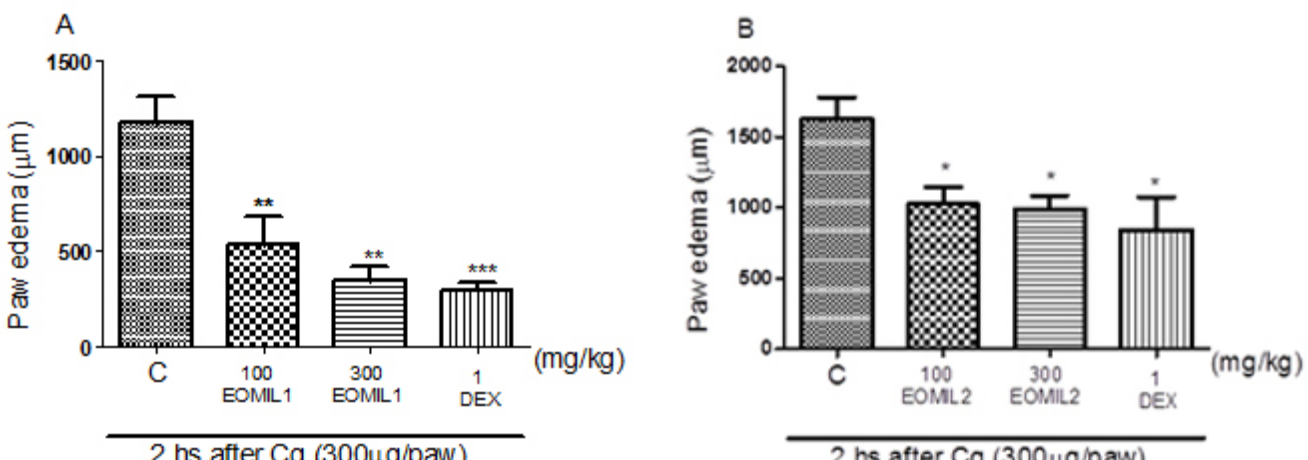

Figure 1. Effect of essential oil of Mangifera indica 1 (EOMIL1) and 2 (EOMIL2) at doses of 100 (A) and 300 (B) $\mathrm{mg} / \mathrm{kg}$ administered orally on carrageenan-induced paw edema in rats. The column represent the two doses inhibition of edema at the time of 120 min after carrageenan injection, which mean of 6 animals and vertical lines show the SE. Asterisks denote the significance levels when compared with control values (carrageenan): ${ }^{*} \mathrm{P}<0.05,{ }^{*} \mathrm{P}<0.01$ and ${ }^{* * *} \mathrm{P}<0.001$.

In Figure 2A $(100 \mathrm{mg} / \mathrm{kg})$ and 2B $(300 \mathrm{mg} / \mathrm{kg})$, it is shown that oral treatment with essential oils from $M$. indica varieties significantly reduced the increase in MPO activity. EOMIL1 and EOMIL2 significantly reduced the MPO activity at doses of $100 \mathrm{mg} / \mathrm{kg}$ (47 \pm 5 and $23 \pm 8 \%$, respectively) and $300 \mathrm{mg} / \mathrm{kg}$ (50 \pm 9 and $31 \pm 7 \%$, respectively). For dexamethasone, the inhibition of MPO activity was found to be $83 \pm 5 \%$ (Figure $2 \mathrm{~A}$ and B).

Genetics and Molecular Research 16 (1): gmr16019227 

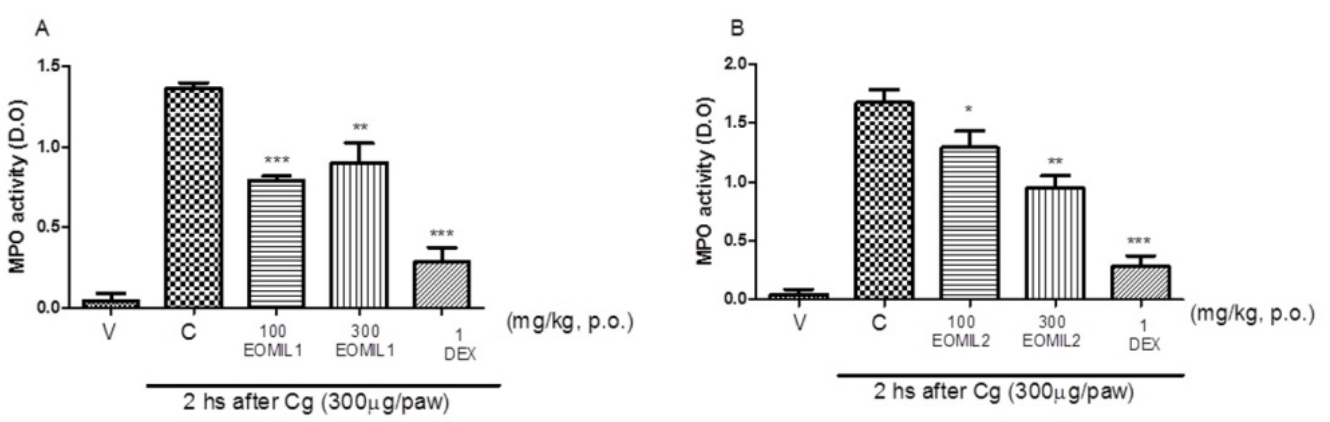

Figure 2. Effect of essential oil of Mangifera indica 1 (EOMIL1) and 2 (EOMIL2) at doses of 100 (A) and 300 (B) $\mathrm{mg} / \mathrm{kg}$ administered orally on carrageenan-induced increase in MPO activity in rats. The column represent the two doses inhibition of edema at the time of $360 \mathrm{~min}$ after carrageenan injection, which mean of 6 animals and vertical lines show the SEM. The comparison of with control versus vehicle group were analyzed by the $t$-test and the symbol \# denoted the statistical differences. Differences between EOMIL1,d EOMIL2 and DEXA treated groups versus control were analyzed by analysis of variance (one-way ANOVA) followed by the Newman-Keuls test and asterisks denote statistic values: $* \mathrm{P}<0.05,{ }^{*} \mathrm{P}<0.01$ and $* * * \mathrm{P}<0.001$.

In Figure $3 \mathrm{~A}$ and $\mathrm{B}$, it is shown that the oral administration of EOMIL1 and EOMIL2 decreased cell migration. Leukocyte migration was assessed in the pleurisy model, and inhibitions of $39 \pm 6$ and $72 \pm 7 \%$ were observed at 100 and $300 \mathrm{mg} / \mathrm{kg}$ of EOMIL1, respectively, while inhibitions of $91 \pm 1$ and $64 \pm 2 \%$ were observed at 100 and $300 \mathrm{mg} / \mathrm{kg}$ of EOMIL2, respectively. However, in the evaluation of plasma extravasation, only EOMIL2 at $100 \mathrm{mg} / \mathrm{kg}$ caused significant reduction (Figure 3).
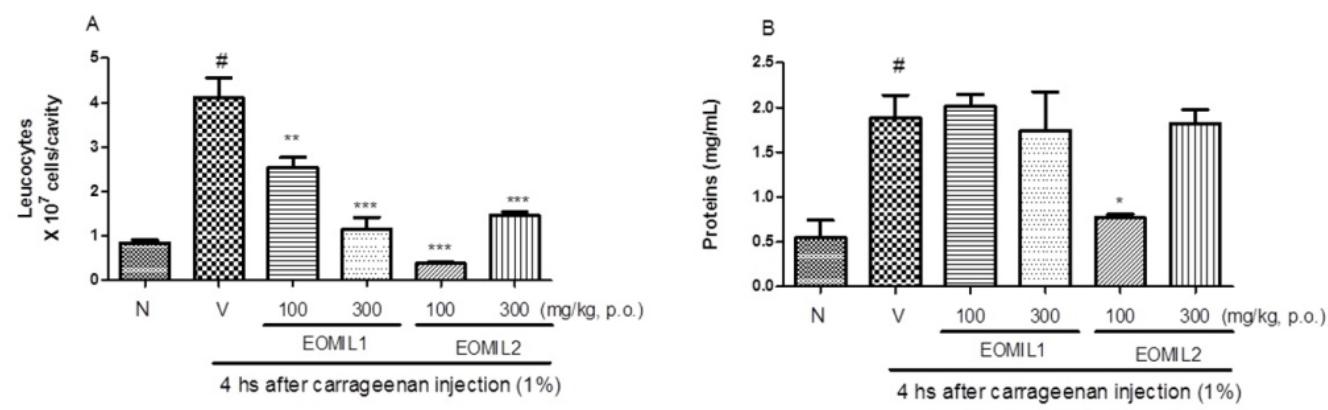

Figure 3. Effects of essential oil of Mangifera indica 1 (EOMIL1) and 2 (EOMIL2) at dose of 100 (A) and 300 (B) $\mathrm{mg} / \mathrm{kg}$ on total leukocytes (A) and protein extravasation (B) induced by carrageenan in the pleural cavity of mice. Animal received the oral treatment with EOMIL1 or EOMIL2 (100 or $300 \mathrm{mg} / \mathrm{kg}$ ), or vehicle, and after $1 \mathrm{~h}$ they received an intrapleural injection of $\mathrm{Cg}(100 \mu \mathrm{L}$ of a $1 \%$ solution/cavity). Control animals received only the vehicles. Animals were killed after Cg injection. The bars express the mean \pm SEM of 6 animals. The comparison of with Naive versus vehicle treated (control) group were analyzed by test $t$ and the symbol \# denoted the statistical differences. Statistical differences between vehicle (V, Control group) versus treated group were denote by asterisks: $* * \mathrm{P}<0.01$ and $* * * \mathrm{P}<0.001$, one-way ANOVA followed by Student-Newman-Keuls.

These results suggest that the $M$. indica varieties espada and coração-de-boi show anti-edematogenic action against the inflammatory agent carrageenan, in addition to reducing MPO activity in the experimental model of inflammation. However, more in-depth studies are

Genetics and Molecular Research 16 (1): gmr16019227 
required to identify the underlying mechanisms of the bioactive compounds and understand their action. These results may be correlated with the presence of major compounds, such as caryophyllene and $\alpha$-humulene. Studies evaluating the anti-inflammatory properties of $\alpha$-humulene and caryophyllene, isolated from Cordia verbenacea essential oil, showed that oral treatment with these compounds exerted inhibitory effects in different inflammatory experimental models in mice and rats. This indicates that these compounds represent important tools for the management or treatment or both of inflammatory diseases (Fernandes et al., 2007).The synergistic effect of chemical compounds of the essential oils should also be taken into consideration for the anti-inflammatory effects.

Although the mechanism of action of terpenes is not fully understood, it is thought to involve membrane disruption by lipophilic compounds (Cowan, 1999). The results of this study may justify the use of $M$. indica leaves as an anti-inflammatory agent in folk medicine.

\section{Conflicts of interest}

The authors declare no conflict of interest.

\section{ACKNOWLEDGMENTS}

The authors are grateful to Conselho Nacional de Desenvolvimento Científico e Tecnológico (CNPq), Coordenação de Aperfeiçoamento de Pessoal de Nível Superior (CAPES) and Fundação de Apoio ao Desenvolvimento do Ensino, Ciência e Tecnologia do Estado do Mato Grosso do Sul (FUNDECT) for financial support and fellowships.

\section{REFERENCES}

Adams RP (2007). Identification of essential oil components by gas chromatography/mass spectrometry. Allured Publishing Corporation, Illinois, USA.

Basha DP, Kuman KP, Teja BB and Subbarao M (2011). Antidiabetic activity on extracts of Mangifera indica in Alloxan monohydrate induced diabetic rats. Drug Invent. Today 3: 165-168.

Hoff Brait DR, Mattos Vaz MS, da Silva Arrigo J, Borges de Carvalho LN, et al. (2015). Toxicological analysis and antiinflammatory effects of essential oil from Piper vicosanum leaves. Regul. Toxicol. Pharmacol. 73: 699-705. http:// dx.doi.org/10.1016/j.yrtph.2015.10.028

Cowan MM (1999). Plant products as antimicrobial agents. Clin. Microbiol. Rev. 12: 564-582.

De Young LM, Kheifets JB, Ballaron SJ and Young JM (1989). Edema and cell infiltration in the phorbol ester-treated mouse ear are temporally separate and can be differentially modulated by pharmacologic agents. Agents Actions 26: 335-341. http://dx.doi.org/10.1007/BF01967298

Deans SG and Waterman PG (1993). Biological Activity of Volatile Oils. In: Volatile oil crops: their biology, biochemistry and production (Hay RKM and Waterman GP, eds.). Longman Scientific \& Technical, Harlow, 97-112.

Dzamic AM, Marin PD, Gbolade AA and Ristic MS (2010). Chemical composition of Mangifera indica essential oil from Nigeria. J. Essent. Oil Res. 22: 123-125. http://dx.doi.org/10.1080/10412905.2010.9700279

Fernandes ES, Passos GF, Medeiros R, da Cunha FM, et al. (2007). Anti-inflammatory effects of compounds alphahumulene and (-)-trans-caryophyllene isolated from the essential oil of Cordia verbenacea. Eur. J. Pharmacol. 569: 228-236. http://dx.doi.org/10.1016/j.ejphar.2007.04.059

Gebara SS, de Oliveira Ferreira W, Ré-Poppi N, Simionatto E, et al. (2011). Volatile compounds of leaves and fruits of Mangifera indica var. coquinho (Anacardiaceae) obtained using solid phase microextraction and hydrodistillation. Food Chem. 127: 689-693. http://dx.doi.org/10.1016/j.foodchem.2010.12.123

Moreno A, Leon DF, Giraldo GA and Rios E (2010). Volatile compounds profile analysis of mango (Mangifera indica $\mathrm{L}$. Var. Tommy Atkins) treated by combined methods. Rev. Colomb. Quim 39: 61-72.

Nikhal S and Mahajan SD (2010). Evaluation of antibacterial and antioxidant activity of Mangifera indica (leaves). $J$.

Genetics and Molecular Research 16 (1): gmr16019227 
Pharm. Sci. Res 2: 45-47.

Pino JÁ, Mesa J, Muñoz Y, Martí MP, et al. (2005). Volatile components from mango (Mangifera indica L.) cultivars. $J$. Agric. Food Chem. 53: 2213-2223. http://dx.doi.org/10.1021/jf0402633

Sharma JN, Samud AM and Asmawi MZ (2004). Comparison between plethysmometer and micrometer methods to measure acute paw oedema for screening anti-inflammatory activity in mice. Inflammopharmacology 12: 89-94. http://dx.doi.org/10.1163/156856004773121400

Velo GP, Dunn CJ, Giroud JP, Timsit J, et al. (1973). Distribution of prostaglandins in inflammatory exudate. J. Pathol. 111: 149-158. http://dx.doi.org/10.1002/path.1711110302

Zimmermann M (1983). Ethical guidelines for investigations of experimental pain in conscious animals. Pain 16: 109110. http://dx.doi.org/10.1016/0304-3959(83)90201-4

Genetics and Molecular Research 16 (1): gmr16019227 